\title{
Gram-negatif Bakteriyemi îlișkili Sepsiste Mortalite Göstergeleri: Pitt Bakteriyemi Skoru, qSOFA, SIRS
}

\section{Prediction of Mortality in Patients with Sepsis Due to Gram-negative Bacteremia: Pitt Bacteremia Score, qSOFA, SIRS}

\author{
Pınar KIRAN' (IID), Ayșe BATIREL ${ }^{2}$ (IID), Serap GENÇER ${ }^{3}$ (IID)
}

\footnotetext{
${ }^{1}$ Dokuz Eylül Üniversitesi Tıp Fakültesi, Halk Sag̃ıg̃ı Anabilim Dalı, Epidemiyoloji Bilim Dalı, İzmir, Türkiye

2 İstanbul Kartal Dr. Lütfi Kırdar Eg̃itim ve Araștırma Hastanesi, İnfeksiyon Hastalıkları ve Klinik Mikrobiyoloji Klinig̃i, İstanbul, Türkiye

${ }^{3}$ Acıbadem Üniversitesi Tıp Fakültesi, İnfeksiyon Hastalıkları ve Klinik Mikrobiyoloji Anabilim Dalı, İstanbul, Türkiye
}

Makale atıfi: Kıran P, Batırel A, Gençer S. Gram-negatif bakteriyemi ilişkili sepsiste mortalite göstergeleri: pitt bakteriyemi skoru, qSOFA, SIRS. FLORA 2021;26(4):663-9.

\section{ÖZ}

Giriş: Sepsis infeksiyona karşı gelişen patolojik, biyokimyasal ve fizyolojik anormalliklerle seyreden sendrom olup yüksek mortalite ve morbiditeyle seyretmektedir. Çalışmamızda gram-negatif bakteriyemi ile ilişkili sepsiste Pitt bakteriyemi skoru, sistemik inflamatuvar yanıt sendromu (SIRS) kriterleri ve quick Sequential Organ Failure Assessment (qSOFA) skorlarının mortaliteyi öngörme gücünü saptamayı amaçladık.

Materyal ve Metod: Mart 2016-Mart 2018 tarihleri arasında acil servisten sepsis tanısılla yatışı yapılan hastalardan kan kültüründe gram-negatif bakteri üremesi olanlar retrospektif olarak incelendi. Hastaların komorbiditeleri, klinik ve laboratuvar verileri, antimikrobiyal tedavileri, SIRS, Pitt bakteriyemi skoru, qSOFA skorları değerlendirildi.

Bulgular: Sepsis-2 tanı kriterlerini karşılayan 106 gram-negatif bakteriyemi ilişkili sepsis tanılı hasta çalışmaya dahil edildi. Otuz günlük mortalite oranı \%20.8'di. Çok değişkenli analiz sonucuna göre Pitt bakteriyemi skoru (OR:1.63, \%95 GA: 1.29-2.05, p< 0.001) mortaliteyi öngörmede anlamlı bağımsız risk faktörü olarak saptandı. Yapılan ROC eğri analizinde Pitt bakteriyemi skoru için eğri altında kalan alan 0.885 (\%95 GA: 0.737-0.933), qSOFA skoru için 0.808 (\%95 GA: 0.713-0.904) ve SIRS için 0.623 (\%95 GA: 0.492-0.753) olarak bulundu. Pitt bakteriyemi skoru diğer skorlamalara göre; en yüksek özgüllüğe (\%71.4) ve en yüksek pozitif prediktif değere (\%40.0) sahipti.

Sonuç: Sonuç olarak çalışmamızda; Pitt bakteriyemi skoru gram-negatif bakteriyemi ilişkili sepsis hastalarında mortaliteyi öngörmede SIRS kriterleri ve qSOFA skoruna göre daha yüksek performansa sahip bulunmuştur.

Anahtar Kelimeler: Pitt bakteriyemi skoru; SIRS; Mortalite; Sepsis 


\title{
ABSTRACT \\ Prediction of Mortality in Patients with Sepsis Due to Gram-negative Bacteremia: Pitt Bacteremia Score, qSOFA, SIRS
}

\author{
Pınar KIRAN', Ayșe BATIREL ${ }^{2}$, Serap GENÇER ${ }^{3}$
}

\footnotetext{
${ }^{1}$ Department of Public Health, Epidemiology Subsection, Dokuz Eylul University Faculty of Medicine, İzmir, Turkey

${ }^{2}$ Clinic of Infectious Diseases and Clinical Microbiology, i̇stanbul Dr. Lütfi Kırdar Training and Research Hospital, i̇stanbul, Turkey

${ }^{3}$ Department of Infectious Diseases and Clinical Microbiology, Acıbadem University Faculty of Medicine, İstanbul, Turkey
}

Introduction: Sepsis is a syndrome of physiologic, biochemical and pathologic abnormalities induced by infection and has been associated with high mortality and morbidity. This study aimed to compare Systemic Inflammatory Response Syndrome (SIRS) criteria, Pitt bacteremia score and quick Sequential Organ Failure Assessment (qSOFA) for the prediction of mortality in patients with sepsis due to Gram-negative bacteremia.

Materials and Methods: Patients with sepsis due to Gram-negative bacteremia admitted to emergency medicine clinic were observed retrospectively from March 2016 to March 2018. Clinical data, laboratory results, co-morbidities, antimicrobial treatment, Pitt bacteremia score, qSOFA score, SIRS criteria of patients were evaluated.

Results: A total of 106 patients with sepsis due to gram-negative bacteremia according to Sepsis-2 definition were included. Thirty-day mortality was 20.8\%. Multivariate analysis determined Pitt bacteraemia score (OR:1.63, 95\% Cl 1.29-2.05, p<0.001) as predictors of mortality among septic patients. The area under the ROC curve was 0.885 (95\% Cl 0.737-0.933) for Pitt bacteremia score 0.808 (95\% $\mathrm{Cl}$ 0.713-0.904) for qSOFA and 0.623 (95\% Cl 0.492-0.753) for SIRS. Pitt bacteremia score showed the highest specificity (\%71.4) and positive predictive value (\%40.0) as compared to other scores.

Conclusion: As the result of the analyses, the mortality rate in patients with sepsis due to gram-negative bacteremia was better predicted with the Pitt bacteremia score than QSOFA score and SIRS criteria.

Key Words: Pitt bacteremia score; SIRS; Mortality; Sepsis

\section{GiRiș}

Çoklu organ yetmezliği ve ölüme yol açabilen sepsisin gün geçtikçe görülme oranı artmakta olup; insidansı 437/100000 kișiye ulașmıs, yaplan küresel tahminlere göre y1llik 31.5 milyon sepsis ve 19.4 milyon ağır sepsis vakası ile 5.3 milyon ölüm öngörümüștür ${ }^{[1]}$. Sistemik inflamatuvar yanıt sendromu (SIRS), ağır sepsis, sepsis, septik sok tanımlamaları ilk olarak 1991 yılında yapılmıs olup, 2002 yilında Uluslararası Sepsis Konferansı'nda tanımlamalar revize edilmiștir ${ }^{[2,3]}$. SIRS kriterlerinin sepsis hastalarını belirleme ve mortaliteyi öngörme gücünün düsük olması nedeniyle en son 2016 yilinda yaplan güncelleme ile ağır sepsis ve SIRS tanımlamalarının kullanımı terk edilmiștir ${ }^{[4]}$. Sepsis; infeksiyona karșı gelișen düzensiz yanıtın yol açtığı hayatı tehdit edici organ bozukluğu olarak tanımlanmıs, SIRS kriterlerinin yerini Sepsis-Related Organ Failure
Assessment' (SOFA) skorlaması almıștır. Yoğun bakım ünitesi dıșında izlenen hastalarda sepsis ilişkili mortaliteyi belirlemede quick SOFA (qSOFA) skorlamasının kullanılması önerilmiștir ${ }^{[4]}$. Solunum sayısı, mental durum bozukluğu ve hipotansiyon olmak üzere bașlıca üç değisskene bağlı olarak hesaplanan qSOFA skorunun 2 ve üzeri olması durumunda hastalarda monitörizasyon sıklığını arttımak ve organ disfonksiyon bulgularını arastırmak gerekmektedir.

Pitt bakteriyemi skoru ise bakteriyemili hastalarda mortaliteyi öngörmede uzun yıllardır kullanilan skorlama sistemi olup; qSOFA skorunda olduğu gibi herhangi bir labaratuvar parametresi olmaksızın hastanın fizik muayene bulguları ile yatak bașında hesaplanabilmektedir ${ }^{[5,6]}$. Hipotansiyon, ates, mental durumda bozulma, mekanik ventilasyon ihtiyacı ve kardiyak arrest olmak üzere basslica bes parametre hesaplamada kullanılmak- 
tadir. Pitt bakteriyemi skorunun 4 ve üzerinde olması yüksek mortalite ile ilișkili olduğu öngörülmektedir. Yaptığımız bu çalıșmamızda gram-negatif bakteriyemi iliskili sepsiste mortalite göstergelerini belirlemeyi, farkl skorlama sistemlerinin mortaliteyi öngörme gücünü saptamayı amaçladı.

\section{MATERYAL ve METOD}

Mart 2016-Mart 2018 tarihleri arasında sepsis tanısıyla acil servisten hastanemiz farklı kliniklerine yatıșı yapılan 18 yaș ve üzeri hastalardan, yatıș günü alınan kan kültüründe gram-negatif üremesi olanlar hastanemiz etik kurul onayı alınarak retrospektif olarak çalıșmaya dahil edildi. Calıșmaya dahil edilen hastaların tümü Sepsis-2 tanı kriterlerini karșılamaktaydı ${ }^{[3]}$. Alınan kültürlerde gram-negatif bakteri dıșında üremesi olanlar, yatış günü ampirik olarak uygun antimikrobiyal tedavi bașlanmayan olgular calıșma dıșı bırakıldı. Kan kültüründe üreyen mikroorganizmaların tanımlanması ve antimikrobiyal duyarlılıklarının belirlenmesi VITEK2 Compact (bioMerieux, Fransa) otomatize sistemi ile yapild. Olguların demografik özellikleri, Charlson komorbidite skoru, infeksiyon bașlangıcındaki klinik ve laboratuvar bulguları, kan kültuirü sonuçları, antibiyotik tedavileri, tedaviye bașlanma zamanı, SIRS, qSOFA ve Pitt bakteriyemi skorları hasta dosyalarından retrospektif olarak kayit edildi. Pitt bakteriyemi skoru her hasta için ateș, kan basıncı, mekanik ventilasyon ihtiyacı, kardiyak arrest, mental durum değișikliği olmak üzere 5 değișkene bağlı olarak hesaplan$\mathrm{dl}^{[5]}$. qSOFA skorunda her biri 1 puan olmak üzere; hipotansiyon $\leq 100 \mathrm{mmHg}$, Glasgow Koma Skalası $(\mathrm{GKS}) \leq 13$, takipne $\geq 22 / \mathrm{dk}$ olmak üzere üc farklı değișkene bakıldı ${ }^{[4]}$. SIRS kriterlerinde; vuicut 1 sisinin $>38^{\circ} \mathrm{C}$ ya da $<36^{\circ} \mathrm{C}$ olması, kalp atım hızının $>90 / \mathrm{dk}$ olması, solunum sayısının $>20 / \mathrm{dk}$ ya da $\mathrm{PaCO}_{2}<32 \mathrm{mmHg}$ olması, lökosit say1sı $>12.000 / \mathrm{mm}^{3}$ ya da $<4000 / \mathrm{mm}^{3}$ ya da $>\% 10$ genc nötrofillerin saptanması olmak üzere 4 kritere bakıldi ${ }^{[2]}$. Sepsis ile birlikte yeterli siv1 replasmanı sonrasinda ortalama arter basincinı $\geq 65 \mathrm{mmHg}$ tutmak için vazopressör kullanım gerekliliği ve serum laktat düzeyinin $>2 \mathrm{mmol} / \mathrm{L}$ olması septik sok olarak tanimlandi ${ }^{[4]}$. Mental durumda bozulma; GKS'nda 2 puan veya daha fazla düșme olarak tanımlandı. Tüm değișkenler için hastanın acil servise bașvurusunun ilk 24 saati içerisindeki en kötü değerleri kayıt edildi. Mortalite, sepsis tanısının 30. gününde meydana gelen ölüm olarak tanımlandı.

İstatistiksel analizler SPSS 26.0 Software programı ile yapılmıs olup; verilerin tanımlayıcı istatistiklerinde ortalama, standart sapma, medyan en düsüuk, en yüksek, frekans ve oran değerleri kullanıld. Kolmogorov-Simirnov testi ile değișken dağılımı hesaplandı. Nitel bağımsız verilerin analizi ki-kare test, ki-kare test kosulları sağlanmadığında ise Fisher's exact test ile yapıldı. Nicel bağım$\mathrm{s} 1 \mathrm{z}$ verilerin analizinde ise bağımsız örneklem $\mathrm{t}$ test, Mann-Whitney $U$ test kullanıld. Etki düzeyi tek değișkenli ve cok değișkenli lojistik regresyon analizi ile değișkenlerin etki düzeyi hesapland. Analiz sonuçları Odds Ratio (OR) ve \%95 güven aralığı (\%95 GA) ve p değeri olarak ile belirtildi. p $<0.05$ değerleri istatistiksel olarak anlamlı kabul edildi. SIRS, qSOFA ve Pitt bakteriyemi skorunun mortaliteyi öngörmedeki performansını belirlemek için Recevier operating characteristics (ROC) eğri analizi yapildi.

\section{BULGULAR}

Mart 2016-Mart 2018 tarihleri arasında acil servisten sepsis tanısıyla yatıșı yapılıp, yatıs günü alınan kan kültüründe gram-negatif üremesi olan 106 hasta calıșmaya dahil edildi. 22 (\%20.8) hasta sepsis nedeniyle kaybedildi. Calıșmamıza alınan olguların 47 (\%44.3)'si kadın, 59 (\%55.7)'u erkek olup ortalama medyan yas 66.6 ( \pm 16.6) olarak bulundu. Hastalarin 69 (\%65.1)'unda Escherichia coli, 19 (\%17.9)'unda Klebsiella spp., 7 (\%6.6)'sinde Pseudomonas aeruginosa, 4 (\%3.8)'ünde Acinetobacter baumannii, 3 (\%2.8)'ünde Enterobacter cloacae, 3 (\%2.8)'ünde Salmonella spp., 1 (\%0.9)'inde Serratia marcescens üremesi saptand. Sağ kalan ve ölen olguların demografik, klinik ve laboratuvar bulgularının karșılaștırılması Tablo 1'de verilmiștir.

Tek değișkenli analiz sonuçlarına göre mortaliteyi öngörmede; qSOFA (OR:3.98, \%95 GA 2.00-7.92, $\mathrm{p}<$ 0.001), Pitt bakteriyemi skoru (OR:1.63, \%95 GA 1.29-2.05, p< 0.001), sistolik kan basıncinın (SKB) $<90 \mathrm{mmHg}$ olması (OR: 4.32, \%95 GA 1.46-12.80, $\mathrm{p}=0.008$ ), antibiyoterapi bașlanma zamanı (OR: 2.93, \%95 GA 1.84-4.67, $\mathrm{p}<0.001$ ) ve mental durumda 
Tablo 1. Sağ kalan ve ölen olguların demografik, klinik ve laboratuvar verilerinin karşılaştırılması

\begin{tabular}{|c|c|c|c|}
\hline & Sağ Kalanlar $(n=84)$ & Ölen Olgular $(n=22)$ & p \\
\hline Yaş & $66.2 \pm 16.1$ & $68.1 \pm 18.7$ & 0.635 \\
\hline \multicolumn{4}{|l|}{ Cinsiyet } \\
\hline Kadın & $39(\% 46.4)$ & $8(\% 36.4)$ & $0.398^{\dagger}$ \\
\hline Erkek & $45(\% 53.6)$ & $14(\% 63.6)$ & \\
\hline \multicolumn{4}{|l|}{ Eşlik eden komorbidite } \\
\hline Diabetes mellitus & $21(\% 25.0)$ & $8(\% 36.4)$ & $0.287^{\dagger}$ \\
\hline Koroner arter hastalığı & $8(\% 9.5)$ & $2(\% 9.1)$ & $0.951^{\dagger}$ \\
\hline Kronik karaciğer hastalığı & $3(\% 3.6)$ & $1(\% 4.5)$ & $1.000^{\dagger}$ \\
\hline Malignite & $34(\% 40.5)$ & $13(\% 59.1)$ & $0.118^{\dagger}$ \\
\hline Kronik böbrek yetmezliği & $18(\% 21.4)$ & $3(\% 13.6)$ & $0.414^{\dagger}$ \\
\hline Hipertansiyon & $34(\% 40.5)$ & $10(\% 45.5)$ & $0.673^{\dagger}$ \\
\hline İmmünsupresyon & $27(\% 32.1)$ & $8(\% 36.4)$ & $0.708^{\dagger}$ \\
\hline Serebrovasküler hastalık & $7(\% 8.3)$ & $3(\% 13.6)$ & $0.449^{\dagger}$ \\
\hline Charlson komorbidite skoru & $2.7 \pm 1.9$ & $2.8 \pm 1.1$ & $0.602^{\ddagger}$ \\
\hline Kronik akciğer hastalığı & $8(\% 9.5)$ & $5(\% 22.7)$ & $0.093^{\dagger}$ \\
\hline \multicolumn{4}{|l|}{ Laboratuvar verileri } \\
\hline Lökosit $\left(/ \mathrm{mm}^{3}\right)\left(\times 10^{3}\right)$ & $15.4 \pm 11.0$ & $16.5 \pm 13.1$ & $0.932^{\ddagger}$ \\
\hline Nötrofil $\left(/ \mathrm{mm}^{3}\right)\left(\times 10^{3}\right)$ & $13.5 \pm 10.0$ & $14.8 \pm 13.5$ & $0.954^{\ddagger}$ \\
\hline CRP (mg/l) & $198.0 \pm 87.9$ & $210.9 \pm 112.59$ & $0.897^{\ddagger}$ \\
\hline Prokalsitonin (ng/mL) & $31.1 \pm 38.7$ & $35.2 \pm 42.3$ & $0.673^{\ddagger}$ \\
\hline Laktat (mmol/l) & $3.0 \pm 2.1$ & $3.6 \pm 2.7$ & $0.504^{\ddagger}$ \\
\hline \multicolumn{4}{|l|}{ Mikrobiyolojik veriler } \\
\hline E. coli & $58(\% 69.0)$ & $11(\% 50.0)$ & $0.095^{\dagger}$ \\
\hline Klebsiella spp. & $12(\% 14.3)$ & $7(\% 31.8)$ & $0.056^{\dagger}$ \\
\hline P. aeruginosa & $5(\% 6.0)$ & $2(\% 9.1)$ & $0.633^{\dagger}$ \\
\hline A. baumannii & $2(\% 2.4)$ & $2(\% 9.1)$ & $0.190^{\dagger}$ \\
\hline Çoklu ilaca dirençli bakteri & $43(\% 51.2)$ & $7(\% 31.8)$ & $0.105^{\dagger}$ \\
\hline \multicolumn{4}{|l|}{ İnfeksiyon başlangıcındaki bulgular } \\
\hline SIRS & $2.5 \pm 0.8$ & $2.9 \pm 0.8$ & $0.059^{\ddagger}$ \\
\hline qSOFA skoru & $1.0 \pm 1.0$ & $2.3 \pm 0.8$ & $<0.001^{\ddagger}$ \\
\hline Pitt bakteriyemi skoru & $1.5 \pm 1.8$ & $5.0 \pm 3.5$ & $<0.001^{\ddagger}$ \\
\hline $\mathrm{SKB}<90 \mathrm{mmHg}$ & $37(\% 44.0)$ & $17(\% 77.3)$ & $0.006^{\dagger}$ \\
\hline Mental durumda bozulma & $33(\% 39.3)$ & $18(\% 81.8)$ & $<0.001^{\dagger}$ \\
\hline Septik şok & $3(\% 3.6)$ & $3(\% 13.6)$ & $0.102^{\dagger}$ \\
\hline \multicolumn{4}{|l|}{ Uygulanan antimikrobiyal tedavi } \\
\hline Başlama zamanı (saat) & $2.3 \pm 1.0$ & $4.2 \pm 1.6$ & $<0.001$ \\
\hline Karbapenem kullanımı & $44(\% 52.4)$ & $9(\% 40.9)$ & $0.368^{\dagger}$ \\
\hline
\end{tabular}


Tablo 2. Gram-negatif bakteriyemi ilişkili sepsiste mortalite risk faktörlerinin tek ve çok değişkenli analizi

\begin{tabular}{lcccccc} 
& \multicolumn{3}{c}{ Tek Değişkenli Analiz } & \multicolumn{3}{c}{ Çok Değişkenli Analiz } \\
\hline & OR & \%95 GA & p & OR & \%95 GA & p \\
\hline Pitt bakteriyemi skoru & 1.63 & $0.13-2.05$ & $<\mathbf{0 . 0 0 1}$ & 1.63 & $0.13-2.05$ & $<\mathbf{0 . 0 0 1}$ \\
qSOFA & 3.98 & $2.00-7.92$ & $<\mathbf{0 . 0 0 1}$ & & & \\
SKB $<90$ mmHg & 4.32 & $1.46-12.80$ & $\mathbf{0 . 0 0 8}$ & & & \\
Tedavi başlanma zamanı (saat) & 2.93 & $1.84-4.67$ & $<\mathbf{0 . 0 0 1}$ & & & \\
Mental durumda bozulma & 6.95 & $\mathbf{2 . 1 6 - 2 2 . 3 8}$ & $<\mathbf{0 . 0 0 1}$ & & & \\
\hline OR: Odds ratio, GA: Güven aralığı. & & & & & &
\end{tabular}

Tablo 3. Gram-negatif bakteriyemi ilişkili sepsiste mortaliteyi öngörmede farklı skorlama sistemlerinin performansı

\begin{tabular}{lccc} 
& Pitt Bakteriyemi Skoru & qSOFA & SIRS \\
\hline EAA & 0.885 & 0.808 & 0.623 \\
\%95 GA & $0.737-0.933$ & $0.737-0.904$ & $0.492-0.753$ \\
Duyarlılı (\%)* & 72.7 & 90.9 & 95.5 \\
Özgüllük (\%)* & 71.4 & 59.5 & 8.3 \\
PPD (\%)* & 40.0 & 37.0 & 21.4 \\
NPD (\%)* & 90.9 & 96.2 & 87.5 \\
\hline
\end{tabular}

EAA: ROC eğrisi altında kalan alan, GA: Güven aralığı, NPD: Negatif prediktif değer, PPD: Pozitif prediktif değer.

*Değerler Pitt bekteriyemi skoru $\geq 4$, qSOFA $\geq 2$, SIRS $\geq 2$ için hesaplanmıştır.

bozulmanın (OR:6.95, \%95 GA 2.16-22.38, p< 0.001) anlamlı etkinliği bulundu (Tablo 2). Cok değiskenli lojistik regresyon analizine göre; Pitt bakteriyemi skoru (OR:1.63, \%95 GA 1.29-2.0, $\mathrm{p}<0.001)$ mortaliteyi öngörmede anlamlı bağımslz risk faktörü olarak saptandı (Tablo 2).

Yapılan ROC eğri analizinde eğri altında kalan alan Pitt bakteriyemi skoru için 0.885 (\%95 GA 0.737-0.933, $\mathrm{p}<0.001$ ), qSOFA skoru için 0.808 (\%95 GA 0.713-0.904, $\mathrm{p}<0.001$ ) SIRS için 0.623 (\%95 GA 0.492-0.753, p< 0.001) saptanmıs olup; Pitt bakteriyemi skoru mortaliteyi öngörmede diğer skorlamalara göre daha güvenilir bulundu. Pitt bakteriyemi skoru 4 "cutoff" değeri için; en yüksek özgülliüğe (\%71.4) ve en yüksek pozitif prediktif değere (PPD) (\%40.0) sahip bulundu. 2 "cut-off" değeri için; SIRS en yüksek duyarlllığa (\%95.5), qSOFA skoru en yüksek negatif prediktif değere (NPD) (\%96.2) sahip bulundu (Tablo 3).

\section{TARTIȘMA}

Gram-negatif bakteriyemi ilișkili sepsiste mortalite göstergesi olarak Pitt bakteriyemi skoru, SIRS ve qSOFA skorlarını karșılaștırdığımız calıșmamızda; Pitt bakteriyemi skoru mortaliteyi öngörmede diğer skorlama sistemlerine göre daha üstün bulundu. Bașta gram-negatif bakteriyemiler olmak üzere; Pitt bakteriyemi skoru yıllardır bakteriyemilerde mortalite göstergesi olarak kullanılmaktadır ${ }^{[5,7,8]}$. Pitt bakteriyemi skoru herhangi bir labaratuvar parametresi gerekmeksizin, yatak başında birkac dakika içerisinde hesaplanan bir skorlama sistemi olup; acil serviste yașamı tehdit eden infeksiyonların hızlıca tanınmasını sağlamaktadır. Son zamanlarda yapilan calıșmalarda Pitt bakteriyemi skoru sepsisli olgularda diğer skorlama sistemlere göre mortaliteyi öngörmede daha üstün bulunmuștur ${ }^{[9]}$. Gram-negatif bakteriyemik 683 olgu ile yapllan bir calıșmada malignite (OR: 3.48, \%95 GA 1.94-6.22), kronik karaciğer yetmezliği (OR: 5.42, \%95 GA 2.52-11.65), üriner sistem ve kateter ilișkili kan dolașımı dıșında diğer infeksiyon odaklarına bağlı bakteriyemi varlığı (OR: 5.54, \%95 GA 2.42-12.69) ve Pitt bakteriyemi skoru $(\geq 4$ için OR: 6.42, \%95 GA 3.11-13.24) 28 günlük mortalite için bağımsı risk faktörü olarak bulunmuștur $^{[10]}$. İsviçre'de 141 bakteriyemi ilișkili sepsis 
olgusuyla yapılan bir çalıșmada; malignite varlığı (OR 3.6; \%95 GA 1.5-8.6), primer kan dolașımı infeksiyonu varlığı (OR 3.4; \%95 GA 1.0-11.1) ve Pitt bakteriyemi skoru (OR 1.8; \%95 GA 1.32.5) 30 günlük mortalite için anlamlı bağımsız risk faktörü olarak saptanırken; SIRS ve SOFA skoru anlamlı bulunmamıștır ${ }^{[11]}$.

Sepsis-3 tanı kriterlerinin ele alındığı 2016'daki konsensüste; mortalite göstergesi olarak SIRS, SOFA ve qSOFA skorları karșlaștırmıs, Pitt bakteriyemi skorundaki değișkenlerin hiçbiri bakteriyemiye özgü olmamasına rağmen calıșmada değerlendirmeye alınmamıștır. YBÜ dıșındaki sepsisli olgularda qSOFA skoru (AUROC $=0.81 ; \% 95$ GA $0.80-0.82 ; \quad p<0.001)$ mortalite göstergesi olarak SIRS (AUROC $=0.76$; \%95 GA 0.75$0.77 ; \mathrm{p}<0.001)$ ve SOFA skorundan (AUROC= 0.79 ; \%95 GA 0.78-0.80; $p<0.001$ ) daha anlamlı bulunmus; acil serviste sepsis süpheli olguları değerlendirirken qSOFA skorunun kullanılması önerilmiștir $^{[4]}$. Bizim calıșmamızda da qSOFA skoru tek değișkenli analizde anlamlı bulunurken, çok değișkenli analizde bağımsız risk faktörü olarak saptanmamıstır. ROC eğri analizi ile skorlamaların değerlendirdiğimizde ise; qSOFA skorunun performansı SIRS kriterlerinden yüksek, Pitt bakteriyemi skorundan düșük bulundu.

23 çalıșmanın incelendiği bir meta-analizde sepsiste hastane mortalitesini öngörmede qSOFA skoru ile SIRS karșlaștırılmıs; qSOFA skorunun daha yüksek özguilliü̆e (\%29'a karș1 \%83), SIRS'nun ise daha yuiksek duyarlılığa (\%51'e karșı \%86) sahip olduğu görülmüștür ${ }^{[12]}$. Bizim calıșmamızda da skorlama sistemleri karșılaștırıldığında; en yüksek duyarlılığa SIRS, en yüksek özgüllüğe ise Pitt bakteriyemi sahip bulundu.

Calıșmamızda gram-negatif bakteriyemi ilișkili sepsis hastalarında mortalite oranını \%20.8 olarak bulmakla birlikte; yapılan farklı calıșmalarda sepsis ile iliskili hastane mortalite oranları \%10-52 arasında saptanmıș olduğu belirtilmiștir [13-15]. 2016 yılında son güncellenen sepsis tanımlamaları ile birlikte SOFA skoru $\geq 2$ artıs olması durumunda mortalite oranı \%10, septik sok tablosunda ise $\% 40$ üzerinde mortalite öngörülmektedir ${ }^{[4]}$.

Olgularımızın tek değișkenli analiz sonucuna göre uygun antibiyoterapi bașlanma zamanı ile mortalite arasında anlamlı ilișki bulunurken; cok değișkenli ileri analizde bağımsız risk faktörü olarak tespit edilmemiștir. 16178 ağır sepsis ve septik soklu hasta ile yapilan bir meta-analizde bir saatten kısa sürede antibiyoterapi bașlanan hastalar ile bes saatten uzun süre sonra antibiyoterapi bașlananlar arasında mortalite açısından anlaml fark saptanmamıstır [16]. Kumar ve arkadașlarının yaptığı bir bașka calıșmada ise; uygun antimikrobiyal tedaviye bașlanmadığı takdirde geçen her saatte sağkalım oranı düștüğü gösterilmiștir ${ }^{[17]}$.

Sepsisli olgularımızda mental durumda bozulma ve hipotansiyon varlığı tek değișkenli analizde anlamlı bulunurken, çok değișkenli lojistik regresyon analizinde bağımsız risk faktörü olarak saptanmamıștır. Song ve arkadașları tarafından yapılan retrospektif bir kohort calıșmasında; ortalama arteriyel kan basincı $(p=0.01)$, sistolik kan basinc1 $(p=0.023)$ ve diastolik kan basinc1 $(p=$ 0.014) tek değișkenli analizde 28 günlük mortalite için anlamlı bulunurken, yapılan ileri analizde bağımsız risk faktörü olarak tespit edilmemiștir ${ }^{[18]}$. Ağır sepsisli olgularla yapılan prospektif bir calıșmada, hastaların GKS düștükçe mortalite oranlar1nın arttığı, GKS= 13 olan olgularda \%20, GKS s8 olan olgularda mortalitenin \%63'e yükseldiŏi gösterilmiștir $(p<0.05)^{[19]}$. Biyıklı ve arkadașları tarafından yapılan gözlemsel çalıșmaya göre 131 sepsis ve septik sok hastasında sistolik kan basınc1, diastolik kan basınc1, GKS ve qSOFA skoruna bakılmıs; yapilan lojistik regresyon analizinde 30 günlük mortalite açısından gruplar arasında anlamlı fark saptanmamıștır [20].

Sonuc olarak gram-negatif bakteriyel sepsisli olgularda acil serviste farklı skorlama sistemlerinin değerlendirildiği calıșmamızda; Pitt bakteriyemi skoru mortalitede bağımsız risk faktörü olarak saptanmıs, SIRS kriterleri ve qSOFA skoruna göre mortaliteyi öngörmede daha yüksek performansa sahip bulunmuștur.

\section{ETIK KURUL ONAYI}

Çalıșma için, Kartal Lütfi Kırdar Eğitim ve Araștırma Hastanesi Klinik Araștırmalar Etik Kurulu'ndan onay alındi (Karar no: 2018/514/126/6, Tarih: 27.03.2018).

\section{ÇIKAR ÇATIŞMASI}

Yazarlar bu makale ile ilgili herhangi bir çkar catıșması bildirmemișlerdir. 


\section{YAZAR KATKISI}

Anafikir/Planlama: PK, AB, SG

Analiz/Yorum: PK, SG

Veri sağlama: $A B, P K$

Yazım: PK, AB, SG

Gözden Geçirme ve Düzeltme: PK, AB, SG

Onaylama: PK, AB, SG

\section{KAYNAKLAR}

1. Fleischmann C, Scherag A, Adhikari NK, Hartog CS, Tsaganos T, Schlattmann P, et al. Assessment of Global Incidence and Mortality of Hospital-treated Sepsis. Current Estimates and Limitations. Am J Respir Crit Care Med 2016 Feb 1;193(3):259-72.

2. American Colege of Chest Physicians/Society of Critical Care Medicine Concensus Conference. Definitions for sepsis and organ failure and guidelines for the use of innovative therapies in sepsis. Crit Care Med 1992;20:864-75.

3. Levy MM, Fink MP, Marshall JC, Abraham E, Angus $D$, Cook D, et al. 2001 SCCM/ESICM/ACCP/ATS/SIS International Sepsis Definitions Conference. Crit Care Med 2003;31:1250-6.

4. Singer $M$, Deutschman CS, Seymour CW, Shankar-Hari $M$, Annane D, Bauer $M$, et al. The Third International Consensus Definitions for Sepsis and Septic Shock (Sepsis-3). Jama 2016;315(8):801-10.

5. Paterson DL, Ko WC, Von Gottberg A, Mohapatra S, Casellas $J M$, Goossens $H$, et al. International prospective study of Klebsiella pneumoniae bacteremia: implications of extended-spectrum beta-lactamase production in nosocomia Infections. Ann Intern Med 2004;140:26-32.

6. Chow JW, Yu VL. Combination antibiotic therapy versus monotherapy for gram-negative bacteraemia: a commentary. Int J Antimicrob Agents 1999;11:7-12.

7. Chow JW, Fine MJ, Shlaes DM, Quinn JP, Hooper DC, Johnson MP, Ramphal $R$, et al. Enterobacter bacteremia: clinical features and emergence of antibiotic resistance during therapy. Ann Intern Med 1991;115:585-90.

8. Korvick JA, Bryan CS, Farber B, Beam TR Jr, Schenfeld L, Muder RR, Weinbaum $D$, et al. Prospective observational study of Klebsiella bacteremia in 230 patients: outcome for antibiotic combinations versus monotherapy. Antimicrob Agents Chemother 1992;36:2639-44.

9. Rhee JY, Kwon KT, Ki HK, Shin SY, Jung DS, Chung DR, Ha $B C$, et al. Scoring systems for prediction of mortality in patients with intensive care unit-acquired sepsis: a comparison of the Pitt bacteremia score and the Acute Physiology and Chronic Health Evaluation II scoring systems. Shock 2009 Feb;31(2):146-5.

10. Al-Hasan MN, Lahr BD, Eckel-Passow JE, Baddour LM. Predictive scoring model of mortality in Gram-negative bloodstream infection. Clin Microbiol Infect 2013 Oct; 19(10):948-54.
11. Papadimitriou-Olivgeris M, Psychogiou R, Garessus J, Camaret $A$, Fourre $N$, Kanagaratnam $S$, Jecker $V$, et al. Predictors of mortality of bloodstream infections among internal medicine patients in a Swiss Hospital: Role of quick Sequential Organ Failure Assessment. Eur J Intern Med 2019 Jul;65:86-92.

12. Song JU, Sin CK, Park HK, Shim SR, Lee J. Performance of the quick Sequential (sepsis-related) Organ Failure Assessment score as a prognostic tool in infected patients outside the intensive care unit: a systematic review and meta-analysis. Crit Care 2018 Feb 6;22(1):28.

13. Martin GS, Mannino DM, Eaton S, Moss M. The epidemiology of sepsis in the United States from 1979 through 2000. N Engl I Med 2003 Apr 17;348(16):1546-54.

14. Kaukonen KM, Bailey M, Suzuki S, Pilcher D, Bellomo R. Mortality related to severe sepsis and septic shock among critically ill patients in Australia and New Zealand, 20002012. JAMA 2014;311(13):1308.

15. Miller RR, Dong L, Nelson NC, Brown SM, Kuttler KG, Probst $D R$, et al. Multicenter implementation of a severe sepsis and septic shock treatment bundle. Am J Respir Crit Care Med 2013;188(1):77.

16. Sterling SA, Miller WR, Pryor J, Puskarich MA, Jones AE. The Impact of Timing of Antibiotics on Outcomes in Severe Sepsis and Septic Shock: A Systematic Review and Meta-Analysis. Crit Care Med 2015 Sep;43(9):1907-15.

17. Kumar A, Roberts D, Wood KE, Light B, Parrillo JE, Sharma $S$, et al. Duration of hypotension before initiation of effective antimicrobial therapy is the critical determinant of survival in human septic shock. Crit Care Med 2006 Jun;34(6):1589-96.

18. Song JE, Kim MH, Jeong WY, Jung IY, Oh DH, Kim YC, Kim JE, et al. Mortality Risk Factors for Patients with Septic Shock after Implementation of the Surviving Sepsis Campaign Bundles. Infect Chemother 2016 Sep;48(3):199-208.

19. Eidelman $L A$, Putterman $D$, Putterman C, Sprung CL. The spectrum of septic encephalopathy. Definitions, etiologies, and mortalities. JAMA 1996;3:470-3.

20. Biyikli E, Kayipmaz AF, Kavalci C. Effect of platelet-lymphocyte ratio and lactate levels obtained on mortality with sepsis and septic shock. Am J Emerg Med 2018 Apr;36(4):64750 .

\section{Yazıșma Adresi/Address for Correspondence}

Dr. Pınar KIRAN

Dokuz Eylül Üniversitesi Tıp Fakültesi,

Halk Sağlığı Anabilim Dalı,

Epidemiyoloji Bilim Dalı,

İzmir-Türkiye

E-posta: drpinaraksoy@gmail.com 